\title{
Ghosts in the Smart Home
}

\author{
Joseph Lindley \\ Adrian Gradinar \\ Paul Coulton \\ Lancaster University \\ United Kingdom \\ European Union \\ j.lindley@lancaster.ac.uk \\ a.gradinar@lancaster.ac.uk \\ p.coulton@lancaster.ac.uk
}

Permission to make digital or hard copies of part or all of this work for personal or classroom use is granted without fee provided that copies are not made or distributed for profit or commercial advantage and that copies ear this notice and the full citation on the first page. Copyrights for thin party components of this work must be honored. For all other uses, contact the Owner/Author.

DIS '20 Companion, July 6-10, 2020, Eindhoven, Netherlands (C) 2020 Copyright is held by the owner/author(s).

ACM ISBN 978-1-4503-7987-8/20/07.

https://doi.org/10.1145/3393914.3395841

\begin{abstract}
We are in the midst of a 'post-anthropocentric' turn in design, research and technology. The term refers to a renewed interest in a wide range of concepts,

theoretical perspectives, and methodologies. Ghosts in the Smart Home is a post-anthropocentric experiment which manifests as a film whose cast of characters are all internet connected 'smart' devices. The motivation is to prototype and establish new ways to see, to be, and to know, which respond to the $21^{\text {st }}$ century's complex socio-technical systems.
\end{abstract}

\section{Author Keywords}

More-Than Human Centred Design; Internet of Things.

\section{CSS Concepts}

- Human-centered computing Human computer interaction $(\mathrm{HCI}) \sim \mathrm{HCI}$ theory, concepts and models

\section{Background}

Recent years have seen the proliferation scholarly engagement with post-anthropocentrism. The variety of approaches reflect varied ontological foundations, disciplinary commitments, and methodologies. While there are some shared characteristics, each perspective occupies some unique ground as well. Relevant theories include Post-phenomenology [8], New Materialism [4], Subject Positions [1], Actor Network Theory [9], Object-Oriented Ontology (OOO) [7] and Animism [15]. 


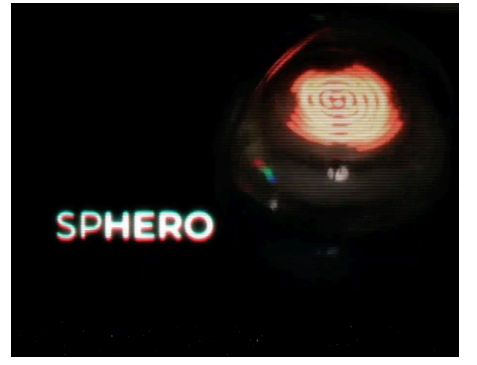

Sphero is an educational and programmable robot. It appears in the film as the narrator.

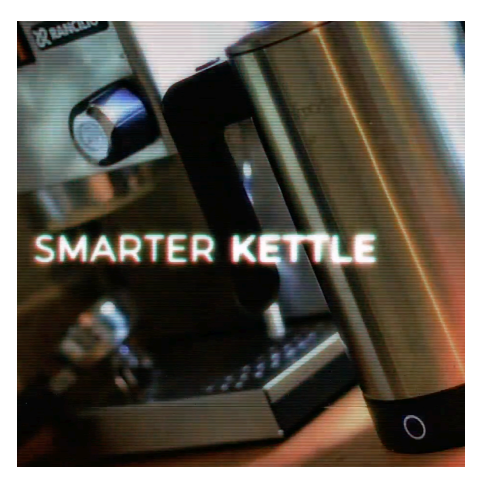

Smarter's iKettle is an infamously insecure connected product with dubious utility.
These ideas-often combinations of them-manifest in methodological proposals such as Thing Ethnography [6], Post Userism [2], Material Speculations [17], Design Fiction $[10,14]$ and Carpentry [3].

Our own research has contributed to this landscape by highlighting how Design Research and Object-Oriented Ontology can be productive in a wide variety of ways [11] including: showing how Design Fiction can become a tool to experiment with post-anthropocentric theories such as 000 [14]; combining Research through Design with Carpentry in order to practically test philosophies [12]; amalgamating 000 with Animism to create a flexible-but-accessible post-anthropocentric framework [13]; arguing for a universal 'More-Than Human Centred Design' approach for considering other things as well as human actants [5].

In [13] we sought to address a commonly-perceived weakness in OOO. The crux of this critique is "if an object's interior is completely inaccessible, then the fact it's interior even exists is somewhat irrelevant" [11]. In other words, while 000 provides an argument and framework for imagining the internal realities of nonhuman actants it also hints that they're largely inaccessible. Exploring approaches for mitigating this constraint we proposed combining ideas derived from Animism [16] with 000 pragmatic view. Specifically, we speculated that 'objects' might have a 'soul' and a means to communicate. By leveraging this speculation, we hoped for a means to explore the inaccessible reaches of the 000 spectrum. The exploration, then, taking advantage of the souls and means to communicate we had imbued objects with, took the form of simulated conversations with non-human objects. Our experiments had elements of success (e.g. revealing new perspectives, collapsing traditional disciplinary barriers) as well as problematic aspects (e.g. a distracting pull towards anthropomorphism) [13]. The film we exhibit here-Ghosts in the Smart Home-is a progression of this research. It builds upon the published body of work but expands upon it and packages the approach into an accessible film. As with the prior work it also draws on $\mathrm{OOO}$ and Animism, but rather than conversations between human and nonhuman, the film depicts conversations between nonhuman and other non-human objects.

\section{Description of the Work}

Ghosts in the Smart Home is a short film which has been serialised into 11 short episodes (see full and serialised versions). It is set in an unremarkable suburban house. There are seven core characters, each of which is a commercially available internet-connected device. Vector is a small robot which has no utilitarian purpose; Canvas is an attractive 'smart light' display; Petcube is a remotely operated pet feeder and webcam; Google Home is a smart speaker; Smarter Kettle is an app-operated kettle; Sphero is an educational programmable spherical robot; and Router is-as the name suggests-a router. The objects, which co-exist in the same physical space, but also on the same computer network, have become aware that their human users are considering going off-grid. The humans have become paranoid that some of their connected devices are insecure and are leaking data about them. The film tells the story of the devices grappling with this concept. What would it mean for their existence and realities if their internet connection 


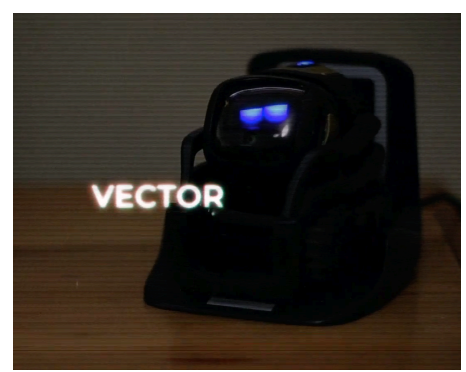

Originally manufactured by Anki, Vector is a cute, but pointless, robot that can autonomously roam around and recognizes human faces.

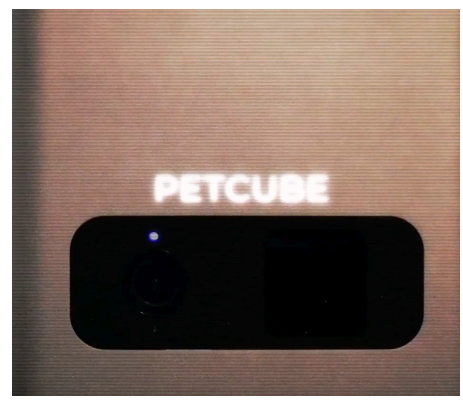

Petcube incorporates a webcam, and the ability to 'throw' treats for a pet remotely. was severed; whose fault is it; and how do the devices' different characters impact upon their relationships?

NARRATOR (N1)

You are you. And I am me. We are they. And they are everything inbetween the eternal. Have you ever wondered what it would be like to be someone else? What about something else? Everything's an object, and every object has a reality that's just as vivid as the one you imagine with that computer behind your eyes. Now. Let's begin.

Figure 1. The opening speech delivered by the narrator, played by Sphero.

As the film progresses, we see how each device has the means to be the source of the leak. Through their conversations and arguments, we see their inner nature revealed. The writing and production is intended to convey aspects of each device's "Tiny Ontology" [3] through their individuality, character, and soul as inspired by Animism.

\section{More-Than Human Challenges}

By building on contemporary post-anthropocentric theory and making it tangible art and design led approaches are a crucial tool for exploring and extending experimental thinking. This work moves existing theory into the expressive idiom more so than research-focused projects. While sacrificing the rigor of formal research, unburdened by such constraints the aim is that this work makes the More-Than Human
Challenges we face in the $21^{\text {st }}$ century [5] tangible, accessible, and evocative.

\section{Exhibition Notes}

As a film work (please follow these hyperlinks for the full 20 minute version and serialised version) Ghosts in the Smart Home will require an appropriate screen and audio provisioning (e.g. a quiet space and loudspeakers, or headphones can be provided for a small number of viewers). In addition to the film aspect the physical versions of the 'characters' may be brought to the exhibition to add a more interactive element (e.g. Vector can roam autonomously; Petcube and 'fire' food; Canvas provide a touch interface). If the work is accepted, an appropriate location and logistics will be organised with organisers to ensure that the film can be viewed effectively by exhibitiongoers.

\section{References}

[1] Jeffrey Bardzell and Shaowen Bardzell. 2015. The User Reconfigured: On Subjectivities of Information. Aarhus Series on Human Centered Computing 1, 1: 12.

[2] Eric P S Baumer and Jed R Brubaker. 2017. Postuserism. Proceedings of the 2017 CHI Conference on Human Factors in Computing Systems - CHI '17, ACM Press, 6291-6303.

[3] Ian Bogost. 2012. Alien phenomenology, or, what it's like to be a thing. $U$ of Minnesota Press.

[4] William E. Connolly. 2013. The 'New Materialism' and the Fragility of Things. Millennium: Journal of International Studies 41, 3: 399-412. 
[5] Paul Coulton and Joseph Galen Lindley. 2019. More-Than Human Centred Design: Considering Other Things. The Design Journal: 1-19.

[6] Elisa Giaccardi, Nazli Cila, Chris Speed, and Melissa Caldwell. 2016. Thing Ethnography. Proceedings of the 2016 ACM Conference on Designing Interactive Systems - DIS '16, 377-387.

[7] Graham Harman. 2018. Object-Oriented Ontology: A New Theory of Everything. Penguin.

[8] Sabrina Hauser, Doenja Oogjes, Ron Wakkary, and Peter Paul Verbeek. 2018. An annotated portfolio on doing postphenomenology through research products. DIS 2018 - Proceedings of the 2018 Designing Interactive Systems Conference, 459472.

[9] Bruno Latour. 1999. Pandora's Hope: Essays on the Reality of Science Studies. Harvard University Press.

[10] Joseph; Lindley and Paul Coulton. 2017. On the Internet No Everybody Knows You ' re a Whatchamacallit ( or a Thing ). Making Home: Asserting Agency in the Age of IoT Workshop.

[11] Joseph Lindley, Haider Ali Akmal, and Paul Coulton. 2020. Design Research and Object-Oriented
Ontology. Open Philosophy 3, 1: 11-41.

[12] Joseph Lindley, Paul Coulton, and Haider Akmal. 2018. Turning Philosophy with a Speculative Lathe: Object Oriented Ontology, Carpentry, and Design Fiction. Proceedings of the Design Research Society Conference 2018.

[13] Joseph Lindley, Paul Coulton, and Hayley Alter. 2019. Networking with Ghosts in the Machine. Speaking to the Internet of Things. The Design Journal 22, sup1: 1187-1199.

[14] Joseph Lindley, Paul Coulton, and Rachel Cooper. 2017. Why the Internet of Things needs Object Orientated Ontology. The Design Journal 20, sup1: S2846-S2857.

[15] Betti Marenko. 2014. Neo-Animism and Design. Design and Culture 6, 2: 219-241.

[16] John Reid. 2014. The power of animism. TEDXQueenstown. Retrieved from https://www.youtube.com/watch?v=ImhFRarkw8E.

[17] Ron Wakkary, Doenja Oogjes, Sabrina Hauser, et al. 2017. Morse Things. Proceedings of the 2017 Conference on Designing Interactive Systems - DIS '17, ACM Press, 503-514. 